\title{
GESTÃO DO CONHECIMENTO EM UMA BIBLIOTECA UNIVERSITÁRIA: DESAFIOS E POTENCIALIDADES
}

\author{
KNOWLEDGE MANAGEMENT AT A UNIVERSITY LIBRARY: CHALLENGES AND \\ POTENTIALITIES
}

\author{
Cristiano Lanza Savegnago \\ Universidade Federal de Santa Maria. RS, Brasil \\ E-mail: cristianolanza@hotmail.com \\ Lorena Inez Peterini Marquezan \\ Universidade Federal de Santa Maria. RS, Brasil \\ E-mail: lorenamarquezan@yahoo.com
}

Recebido em: 10.12.2018 - Aceito em: 27.08.2019

DOI: http://dx.doi.org/10.5902/2526629235983

\section{RESUMO}

Este artigo, teórico-impírico de natureza qualitativa, é o resultado da análise da Gestão do Conhecimento no contexto de uma biblioteca universitária de uma Instituição Federal de Ensino Superior (IFES). Os dados foram coletados por meio de entrevistas semiestruturadas realizadas com os gestores (diretor e chefias de divisões). A análise foi realizada utilizando-se o modelo de diagnóstico de Gestão do Conhecimento em bibliotecas universitárias proposto por Castro (2005) e, como técnica para interpretar os resultados, utilizou-se a Análise Textual Discursiva (ATD) de Moraes (2003). Os resultados permitiram identificar que os Processos de Gestão do Conhecimento ocorrem de maneira não estruturada e que os Suportes Organizacionais necessitam ser aprimorados, especialmente, a Gestão de Pessoas e as ferramentas de Tecnologia da Informação (TI).

PALAVRAS-CHAVE: Gestão do Conhecimento; Organizações Públicas; Biblioteca Universitária.

\section{ABSTRACT}

This article, theoretical-empirical of qualitative nature, is the result of the Knowledge Management analysis in the context of a university library of a Federal Institution of Higher Education (IFES). Data were collected through semi-structured interviews with the managers (director and heads of department). The analysis was carried out 
using the Knowledge Management model at University Libraries proposed by Castro (2005), and the Discursive Textual Analysis suggested by Moraes (2003) was used to interpret the results. The results allowed to identify that the processes of knowledge management occur in an unstructured way, and that organizational support needs to be improved, especially people management and Information Technology (IT) tools.

KEYWORDS: Knowledge Management; Public Organizations; University Library.

\section{INTRODUÇÃO}

As transformações tecnológicas e informacionais que ocorreram nos últimos tempos acentuaram a velocidade da informação e acirraram a competição entre as organizações. Nesse contexto, gerir com excelência os conhecimentos dos colaboradores torna-se essencial, pois o conhecimento representa o único ativo que aumenta cada vez mais a partir de sua utilização (Probst, Raub \& Romhardt, 2002).

Em vista da importância do conhecimento, emerge a Gestão do Conhecimento, a qual pode ser compreendida como o conjunto de atividades relacionadas à geração, à codificação e à transferência do conhecimento (Davenport \& Prusak, 1998). A Gestão do Conhecimento possibilita estabelecer canais estruturados de troca de informações e conhecimentos entre os colaboradores, otimizando as rotinas administrativas e os processos de trabalho.

No âmbito das organizações públicas, pode ser utilizada para auxiliar no enfrentamento dos novos desafios e na melhoria da qualidade dos processos, dos produtos e dos serviços em benefício do cidadão-usuário (Batista, 2012). Desse modo, a Gestão do Conhecimento pode ser adotada nos diferentes tipos de organizações, sejam elas públicas ou privadas.

A biblioteca universitária, além de ser a instância responsável pela gestão do patrimônio informacional da instituição a qual pertence, também pode ser considerada uma organização, tendo seus objetivos e finalidades, relacionados à disseminação da informação e à busca da satisfação das diferentes demandas da comunidade universitária (Maciel \& Mendonça, 2006). Portanto, a Gestão do Conhecimento pode auxiliá-la no desenvolvimento, no compartilhamento e no uso do conhecimento de seus colaboradores, a fim de melhorar a qualidade e a eficiência dos serviços oferecidos aos usuários.

Na literatura é possível encontrar diversos estudos sobre Gestão do Conhecimento em bibliotecas universitárias, dentre os quais se destaca a dissertação de Castro (2005), que elaborou um instrumento de diagnóstico de Gestão do Conhecimento específico para essa instância acadêmica. 
A pesquisa de mestrado de Silva (2013) teve como intenção a proposição de um instrumento para diagnosticar a Gestão da Informação e do Conhecimento (GIC) de forma integrada para as bibliotecas universitárias. Os resultados indicaram que há necessidade de explorar, com profundidade, as temáticas específicas da GIC, tais como a valorização do capital intelectual dos servidores. Ainda ficou evidenciado que o processo de Gestão da Informação e do Conhecimento depende de ações bem planejadas, alinhadas às expectativas organizacionais e dos usuários, através do uso de recursos humanos, materiais e tecnológicos.

A tese de Bem (2015) objetivou o desenvolvimento de uma ferramenta para trabalhar a Gestão do Conhecimento nas bibliotecas universitárias, denominada de Framework de Gestão do Conhecimento para Bibliotecas Universitárias (GCBU).

Santos (2015) buscou analisar como as ações de Gestão da Informação e do Conhecimento podem contribuir para melhorar as atividades de mediação da informação nos dispositivos de comunicação da web social das bibliotecas universitárias. Os resultados evidenciaram que a Gestão do Conhecimento possibilita o melhor atendimento aos usuários, a criação de um ambiente propício à participação e à interação; o incentivo e a motivação ao debate, o compartilhamento de conhecimentos e experiências e a apresentação de ideias e sugestões.

O trabalho de Rossi et al. (2017) buscou aplicar o Framework GCBU, especificamente o "Módulo Coordenação de Gestão do Conhecimento" no âmbito da biblioteca universitária da Universidade Federal de Santa Catarina (UFSC). Seus resultados apontaram que os colaboradores começaram a participar de forma mais efetiva de treinamentos e capacitações, resultando na melhoria na comunicação e na interação da equipe.

Considerando a relevância dessa temática no âmbito das bibliotecas universitárias, este estudo tem como objetivo compreender como ocorre a Gestão do Conhecimento na Biblioteca Central da Universidade Federal de Santa Maria (UFSM). Para tanto, utilizou-se o modelo de diagnóstico da Gestão do Conhecimento em bibliotecas universitárias proposto por Castro (2005), uma vez que a referida ferramenta se mostra adequada ao objetivo proposto.

Como forma de melhor operacionalizar o trabalho, o presente artigo foi dividido da seguinte forma: no item 2, aprofunda-se conceitos teóricos sobre a Gestão do Conhecimento e seus modelos; no item 3, discorre-se sobre a metodologia utilizada no estudo; no item 4, apresenta-se a análise e a discussão dos resultados e, por fim, no item 5 , tem-se as considerações finais do trabalho. 


\section{REFERENCIAL TEÓRICO}

Nesta seção abordam-se alguns aspectos conceituais da Gestão do Conhecimento, bem como apresentam-se alguns de seus modelos.

\subsection{Gestão do Conhecimento: aspectos conceituais}

No final da década de 1990, autores como Nonaka e Takeuchi (1997), Sveiby (1998), Davenport e Prusak (1998), entre outros, aprofundaram a temática Gestão do Conhecimento no âmbito organizacional, tornando-se referência nas pesquisas que abordam o assunto. Para uma melhor compreensão da Gestão do Conhecimento, é importante fazer a distinção entre os elementos que compõem esse processo: dado, informação e conhecimento.

No entendimento de Davenport e Prusak (1998), dados referem-se a um conjunto de fatos distintos e objetivos, relativos a eventos, os quais em um contexto organizacional, podem ser descritos como registros estruturados de transações. Com relação à informação, essa tem a finalidade de mudar o modo como o destinatário observa algo, exercendo algum impacto sobre seu julgamento e comportamento, ou seja, a informação pode ser compreendida como um conjunto de dados com relevância e propósito (Davenport \& Prusak, 1998).

O conhecimento, por seu turno, é o resultado da combinação de informação, contexto e experiência individual e pode ser conceituado como:

\footnotetext{
Uma mistura fluida de experiência condensada, valores, informação contextual e insight experimentado, a qual proporciona uma estrutura para avaliação e incorporação de novas experiências e informações. Ele tem origem e é aplicado na mente dos conhecedores. Nas organizações, ele costuma estar embutido não só em documentos ou repositórios, mas também em rotinas, processos, práticas e normas organizacionais (Davenport \& Prusak, 1998, p. 6).
}

Conforme fica evidenciado, no âmbito organizacional, o conhecimento poderá estar em documentos e repositórios, mas também existe no interior das pessoas e apresenta-se na forma tácita. De acordo com Nonaka e Takeuchi (2008), o conhecimento organizacional é criado a partir da interação entre o conhecimento tácito e o explícito, sendo que o conhecimento explícito pode ser expresso em palavras, números ou sons e compartilhado na forma de dados, de fórmulas científicas e de manuais, podendo ser transmitido aos indivíduos de maneira formal e sistêmica.

O conhecimento tácito, por sua vez, não é visível, mas explicável, pois é pessoal e difícil de ser formalizado, uma vez que está enraizado nas ações, nas 
experiências, nos valores e nas emoções dos indivíduos (Nonaka \& Takeuchi, 2008). O conhecimento tácito é algo que as pessoas, às vezes, não têm a real noção, ou seja, "as pessoas sabem mais do que têm consciência de saber ou são capazes de exprimir por palavras" (Sveiby, 1998, p. 48). De acordo com Nonaka e Takeuchi (2008), a partir da interação entre o conhecimento tácito e o explícito ocorre a criação do conhecimento organizacional. Para esses autores, isso ocorre por meio de quatro processos de transformação do conhecimento: socialização, externalização, combinação e internalização.

A socialização "é o processo de compartilhamento de experiências e, com isso, de criação de conhecimento tácito, tais como os modelos mentais e as habilidades técnicas compartilhadas" (Nonaka \& Takeuchi, 2008, p. 60). O processo de articulação do conhecimento tácito em conceitos explícitos, em que o conhecimento tácito pode ser traduzido por meio de metáforas, de analogias, de hipóteses ou de modelos compreende a externalização.

A combinação é um processo de sistematização de conceitos em um sistema de conhecimentos que envolve a combinação de diversos conhecimentos explícitos. Pode ocorrer através de documentos, de reuniões, de conversas telefônicas ou de redes de comunicação computadorizada (Nonaka \& Takeuchi, 2008).

A última etapa do processo de transformação do conhecimento compreende a internalização, a qual ocorre por meio da conversão do conhecimento explícito em conhecimento tácito e, segundo os autores, é o "aprender fazendo". Dessa forma, tem-se a partir da interação contínua e dinâmica entre o conhecimento tácito e o explícito a criação do conhecimento organizacional (Nonaka \& Takeuchi, 2008).

Para Jorge e Sutton (2016), criar novos conhecimentos passou a ser fundamental no contexto das organizações e tal fato ocorre devido à compreensão de que a criação do conhecimento propicia às organizações vantagens competitivas.

Nesse contexto, o conjunto de esforços ordenados e sistematizados que visa criar novo conhecimento, difundi-lo na organização para os que dele necessitam e incorporá-lo a produtos e serviços pode ser definido como Gestão do Conhecimento (Lacombe \& Heilborn, 2008).

Em organizações de conhecimento, como bibliotecas, a Gestão do Conhecimento também é necessária, uma vez que permite gerenciar o conhecimento do usuário (suas necessidades, quem contatar para busca de informações), o conhecimento dos recursos (fontes, serviços e onde esses serviços estão disponíveis) e o conhecimento prático das pessoas (expertise disponível, a qualidade do serviço que prestam) entre outros (Islam, Agarwal \& Ikeda, 2017). Afinal, o sucesso de uma 
biblioteca depende da capacidade de utilizar o conhecimento de sua equipe para atender à comunidade de usuários, ao mesmo tempo em que gerencia os processos de criação, disseminação e possível exploração do conhecimento (Marouf, 2017).

\subsection{Modelos de Gestão do Conhecimento}

O modelo de Gestão do Conhecimento proposto por Probst, Raub e Romhardt (2002) envolve oito elementos construtivos divididos em seis processos essenciais e dois elementos estratégicos, conforme pode ser observado na Figura 1.

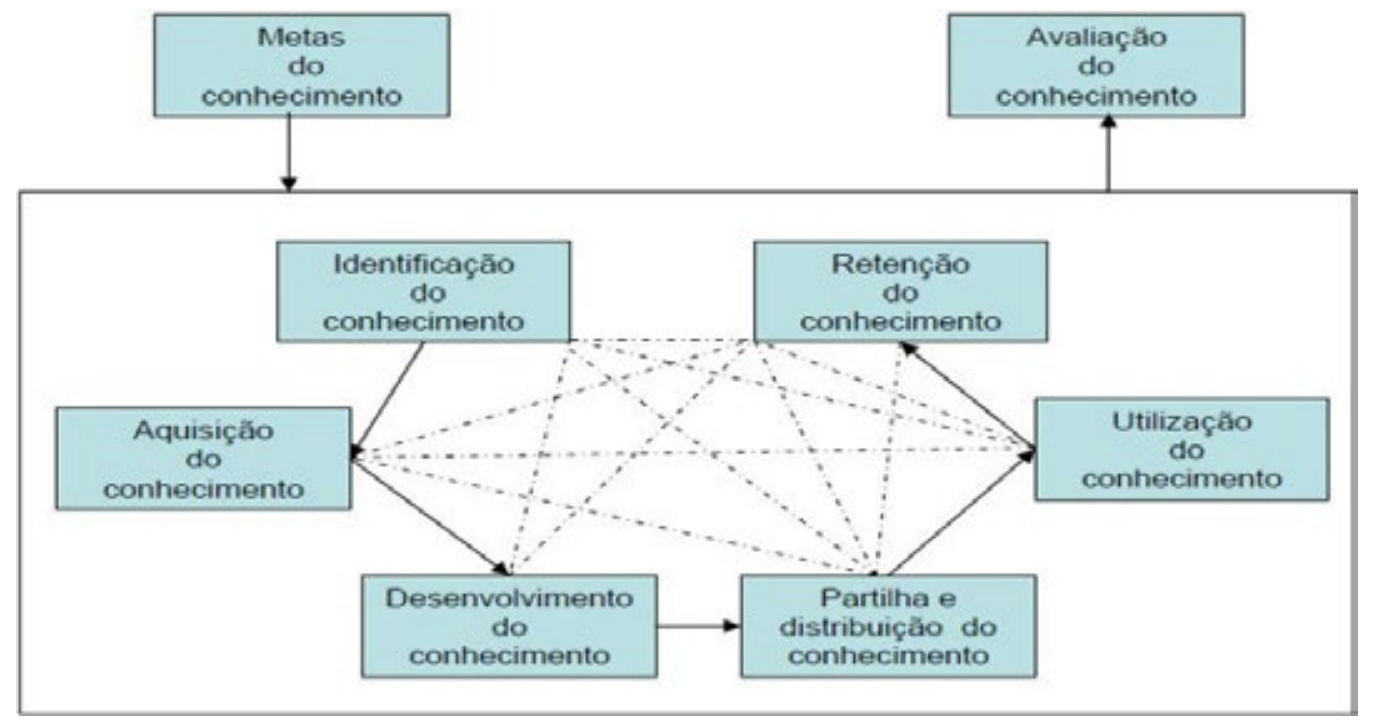

Figura 1 - Elementos construtivos da Gestão do Conhecimento Fonte: Probst, Raub e Romhardt (2002, p. 36).

No modelo dos autores, o elemento Identificação do Conhecimento possibilita a análise e a descrição do ambiente de conhecimento da organização para melhor definir o quadro de habilidades, de informações e de dados internos e externos. A Aquisição do Conhecimento tem como propósito identificar o conhecimento que a organização não consegue desenvolver internamente e, a partir de então, buscá-lo através de relações com agentes externos.

No que tange ao Desenvolvimento do Conhecimento, este é utilizado como complemento da aquisição do conhecimento, sendo que seu enfoque está em desenvolver novas ideias, novas habilidades e novas competências para que os processos se tornem mais eficientes.

A Partilha e Distribuição do Conhecimento possibilitam a transformação de informações e experiências isoladas em algo que possa ser utilizado por toda 
a organização. Permite que os membros da equipe compartilhem seus conhecimentos e aprendam assuntos que podem ser de fundamental interesse para as equipes futuras que tratam assuntos semelhantes.

O elemento Utilização do Conhecimento compreende a implementação do processo de Gestão do Conhecimento, enquanto a Retenção do Conhecimento objetiva reter seletivamente informações, documentos e experiências, mas, para isso, é necessária uma boa gestão desses conhecimentos.

As Metas de Conhecimento explicam a orientação estratégica da Gestão do Conhecimento e os objetivos concretos de intervenções específicas, buscando desenvolver as habilidades em níveis normativos, estratégicos e operacionais. Por fim, a Avaliação do Conhecimento completa o sistema e representa o momento em que a organização deve mensurar o quanto a Gestão do Conhecimento é eficiente (Probst, Raub \& Romhard, 2002).

Outro modelo a ser destacado é o descrito por Angeloni (2008), que considera a organização do conhecimento sob uma perspectiva holística, composta por três dimensões que são interagentes e interdependentes. As três dimensões compreendem a infraestrutura organizacional, as pessoas e a tecnologia. A Dimensão Infraestrutura Organizacional é formada por todos os elementos que sustentam a manutenção e a continuidade da organização (Angeloni, 2008). Essa dimensão contempla as crenças, os princípios, a postura, o estilo gerencial, a estrutura e a cultura organizacional, entre outros.

A Dimensão Pessoas é constituída pelas variáveis de aprendizagem, relacionada à mudança no comportamento da pessoa, pela incorporação de novos hábitos, atitudes, conhecimentos e habilidades, ou seja, modelos mentais que são responsáveis pelo modo de compreender e agir no mundo. Por fim, a Gestão do Conhecimento é representada pela Dimensão Tecnologia que está relacionada ao uso de computadores, redes (internet, intranet e extranet) e softwares que apresentam a função de armazenar, de recuperar e de difundir conhecimentos, tanto aqueles acumulados quanto os que ainda estão em fase de desenvolvimento.

No âmbito das bibliotecas universitárias, destaca-se o estudo de Castro (2005), o qual elaborou um instrumento de diagnóstico da Gestão do Conhecimento em bibliotecas universitárias, conforme ilustrado na Figura 2. 


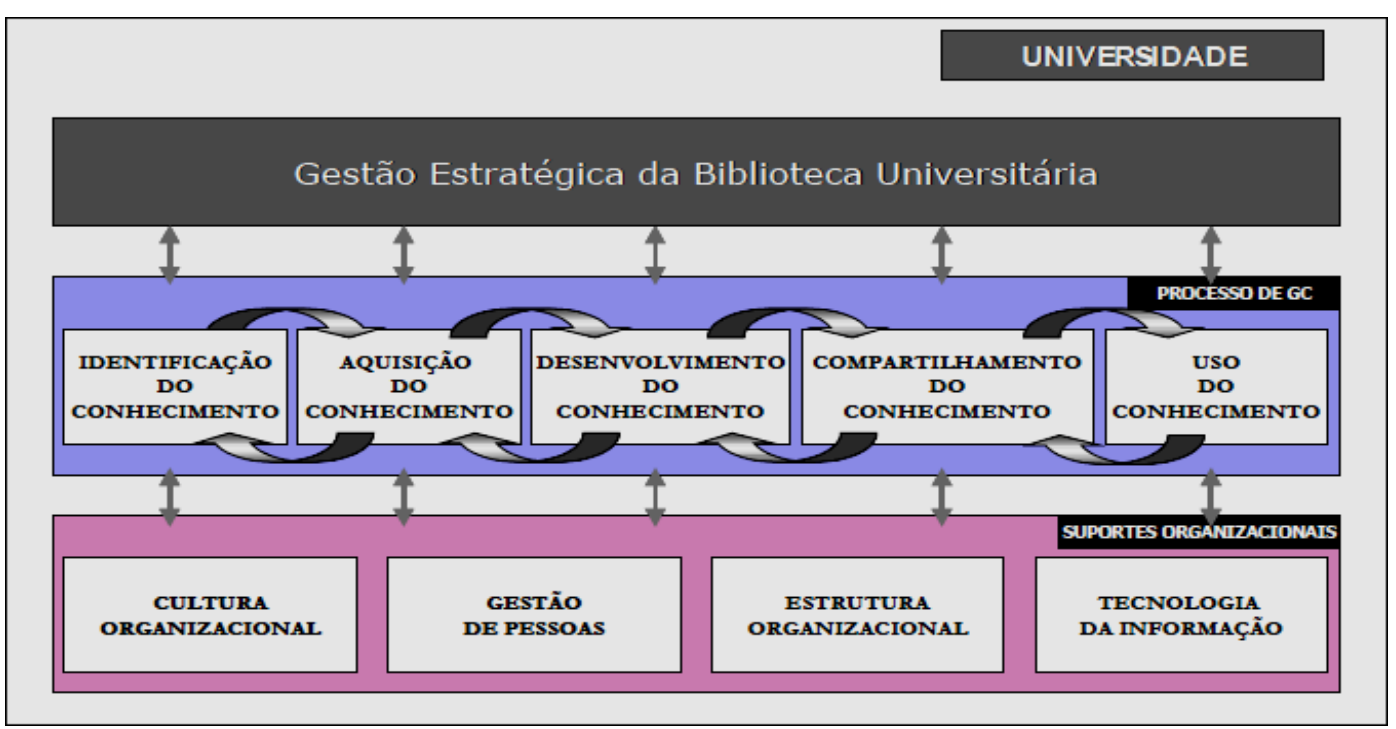

Figura 2 - Elementos básicos para a Gestão do Conhecimento em bibliotecas universitárias Fonte: Castro (2005, p. 100).

De acordo com o instrumento proposto pela autora, os Processos de Gestão do Conhecimento compreendem cinco elementos (Identificação, Aquisição, Desenvolvimento, Compartilhamento e Uso do Conhecimento), os quais serão detalhados a seguir.

Sobre o elemento Identificação do Conhecimento, Castro (2005) entende que um projeto de gestão do conhecimento deve iniciar pela discussão sobre quais conhecimentos são essenciais para a organização. No Quadro 1, são apresentados os requisitos que auxiliam na identificação dos conhecimentos.

\section{REQUISITOS}

1. Identificação de quais conhecimentos e habilidades suportam as core competencies escolhidas.

2. Mapeamento de conhecimentos existentes na biblioteca universitária.

3. Mapeamento de competências existentes na biblioteca universitária.

4. Identificação das fontes internas e externas de conhecimento.

5. Promover internamente a transparência de conhecimento existente na organização.

6. Identificação das lacunas de conhecimento.

Quadro 1 - Requisitos de Identificação do Conhecimento

Fonte: Castro (2005, p.106).

A Aquisição do Conhecimento destina-se a suprir aqueles conhecimentos que não são desenvolvidos pela organização. De acordo com Castro (2005), o processo de aquisição representa a apropriação de conhecimentos de fontes internas e fontes externas à organização, conforme disposto no Quadro 2. 


\section{REQUISITOS}

1. Definir e selecionar as estratégias de aquisição de conhecimento.

2. Estabelecer formas de adquirir conhecimento de fontes internas.

3. Estabelecer formas de adquirir conhecimento de fontes externas.

4. Verificar a aquisição de conhecimento externo, antes de um projeto de desenvolvimento.

5. Registrar os conhecimentos adquiridos pela biblioteca universitária.

6. Possuir formas de armazenamento que suportem a aquisição de conhecimento.

Quadro 2 - Requisitos de Aquisição de Conhecimento

Fonte: Castro (2005, p. 108).

Em relação ao Desenvolvimento do Conhecimento, Castro (2005) considera que esse elemento representa a complementação da aquisição, tendo como enfoque o desenvolvimento de novas habilidades, de novos produtos e de novos processos mais eficientes. Os requisitos de desenvolvimento do conhecimento estão dispostos no Quadro 3.

\section{REQUISITOS}

1. Identificar locais de desenvolvimento de conhecimento na biblioteca universitária. 2.Estabelecer políticas de desenvolvimento de conhecimento ligadas aos objetivos da organização.

3. Criar condições de interação e comunicação entre os participantes da organização. 4. Estabelecer parcerias com diferentes profissionais e organizações para gerar novos conhecimentos.

Quadro 3 - Requisitos de Desenvolvimento do Conhecimento

Fonte: Castro (2005, p. 110).

O Compartilhamento do Conhecimento na visão de Castro (2005) representa o elemento central do processo de gestão do conhecimento, pois propicia a troca de experiências e sabedoria, transferindo o know-how que cada integrante possui dentro da organização. No Quadro 4, encontram-se os requisitos para verificar o compartilhamento do conhecimento.

\section{REQUISITOS}

1. Identificar e compartilhar as habilidades e competências da biblioteca universitária.

2. Definir métodos formais de compartilhar o conhecimento dos participantes da organização.

3. Criar e incentivar uma cultura organizacional de compartilhamento de conhecimento.

4. Determinar formas de motivação e encorajamento para o compartilhamento de conhecimento.

5. Construir e manter por meio de tecnologia da informação sistemas que suportem o compartilhamento do conhecimento.

Quadro 4 - Requisitos de Compartilhamento do Conhecimento

Fonte: Castro (2005, p. 111). 
Em relação ao Uso do Conhecimento, este representa o elemento que possibilita que todo o conhecimento criado, adquirido e compartilhado no âmbito da organização, torne-se utilizável, pois para ter valor o conhecimento necessita ser aplicado. Os requisitos para a identificação de como acontece o processo de Uso do Conhecimento em bibliotecas estão elencados no Quadro 5.

\section{REQUISITOS}

1. Estabelecer políticas e incentivos para o uso do conhecimento organizacional armazenado.

2. Criar infraestruturas tecnológicas que facilitem e auxiliem o uso do conhecimento.

3. Estabelecer centros de conhecimento e informação organizacional.

4. Ampliar o uso do conhecimento por meio de novos serviços e produtos informacionais. Quadro 5 - Requisitos de Uso do Conhecimento

Fonte: Castro (2005, p.112).

Para que os processos ora elencados possam ocorrer, é necessário um suporte por parte da instituição, os chamados Suportes Organizacionais. Os quatro suportes definidos pela autora são: a) Cultura Organizacional; b) Gestão de Pessoas; c) Estrutura Organizacional e d) Tecnologia da Informação;

Com base no exposto, a Gestão Estratégica da Biblioteca, os Processos de Gestão do Conhecimento e os Suportes Organizacionais representam os elementos que compõem o modelo proposto por Castro (2005), o qual possibilitou a elaboração de um instrumento para realizar um diagnóstico abrangente da Gestão do Conhecimento em bibliotecas universitárias.

\section{METODOLOGIA DE PESQUISA}

Este estudo foi desenvolvido utilizando-se uma pesquisa exploratória descritiva com abordagem qualitativa. A etapa exploratória foi composta por uma revisão bibliográfica por meio de livros sobre o tema, bem como através da produção científica sobre a gestão do conhecimento no contexto das bibliotecas universitárias.

Em relação aos procedimentos técnicos, a estratégia adotada foi o estudo de caso. O estudo de caso é um procedimento metodológico que busca explicar "como" ou "por que razão" uma circunstância ocorre, sendo um método relevante quando se necessita de uma descrição mais ampla e profunda de um evento (Yin, 2015). Com o mesmo entendimento, Gil (2002) declara que o estudo de caso é um estudo profundo e exaustivo de um ou alguns objetos de maneira a permitir o seu conhecimento amplo e detalhado. No caso em questão, o objeto de análise referese à biblioteca central da UFSM, tendo como sujeitos da pesquisa o diretor e as 
chefias de divisões. A amostra foi escolhida por acessibilidade, que segundo Gil (2002), constitui o mais flexível de todos os tipos de amostragem, pois é destituída de qualquer rigor estatístico. No entanto, cabe destacar a importância das pessoas selecionadas para os propósitos do estudo, haja vista o cargo que ocupam e o seu grau de responsabilidade na referida unidade de análise.

A coleta de dados foi realizada por meio de entrevistas semiestruturadas, tendo como roteiro tópicos selecionados do instrumento de diagnóstico elaborado por Castro (2005). Compuseram o roteiro 18 perguntas, sendo 6 sobre o perfil dos entrevistados e 12 questões sobre aspectos técnicos relacionados à Gestão do Conhecimento, tendo como variáveis investigadas: Identificação, Aquisição, Desenvolvimento, Compartilhamento e Uso do Conhecimento. Além disso, buscouse verificar aspectos relacionados aos Suportes Organizacionais, como: Cultura Organizacional, Gestão de Pessoas, Estrutura Organizacional e Tecnologia da Informação. As entrevistas foram realizadas no mês de setembro de 2018. O perfil dos gestores entrevistados e o tempo de duração encontram-se detalhados no Quadro 6.

\begin{tabular}{|c|c|c|c|c|}
\hline Idade & $\begin{array}{c}\text { Tempo de } \\
\text { instituição }\end{array}$ & Setor de Trabalho & Escolaridade & $\begin{array}{c}\text { Duração } \\
\text { aproximada da } \\
\text { entrevista }\end{array}$ \\
\hline 47 anos & 7 anos & Direção & Mestrado & 38 minutos \\
\hline 30 anos & 2 anos & Divisão de Aquisição & Graduação & 26 minutos \\
\hline 39 anos & 1 ano & $\begin{array}{c}\text { Divisão de Processos } \\
\text { Técnicos }\end{array}$ & Graduação & 28 minutos \\
\hline 35 anos & 1 ano & Divisão de Referência & Mestrado & 25 minutos \\
\hline
\end{tabular}

Quadro 6 - Perfil dos entrevistados e duração da entrevista.

Fonte: Elaborado pelos autores.

Escolheu-se esse tipo de entrevista (semiestruturada) em função da necessidade de um instrumento ao mesmo tempo direcionado e flexível que possibilitasse esclarecimentos e aprofundamento sobre outras questões relevantes que surgissem no decorrer das intervenções. As transcrições das entrevistas foram analisadas e categorizadas com base na Análise Textual Discursiva (ATD) de Moraes (2003) por meio das seguintes etapas: (1) desconstrução e unitarização; (2) estabelecimento de relações ou categorização e (3) captação do novo emergente. Para esse autor, as categorias (na análise textual) podem ser produzidas por diferentes métodos, sendo que no método dedutivo as categorias são deduzidas das teorias que fundamentam a pesquisa, enquanto no método indutivo as categorias resultam da análise dos dados produzidos especificamente para o estudo. Nesta 
pesquisa, as categorias e subcategorias foram deduzidas a partir do instrumento de diagnóstico de Gestão do Conhecimento proposto por Castro (2005), conforme ilustrado na Figura 3.

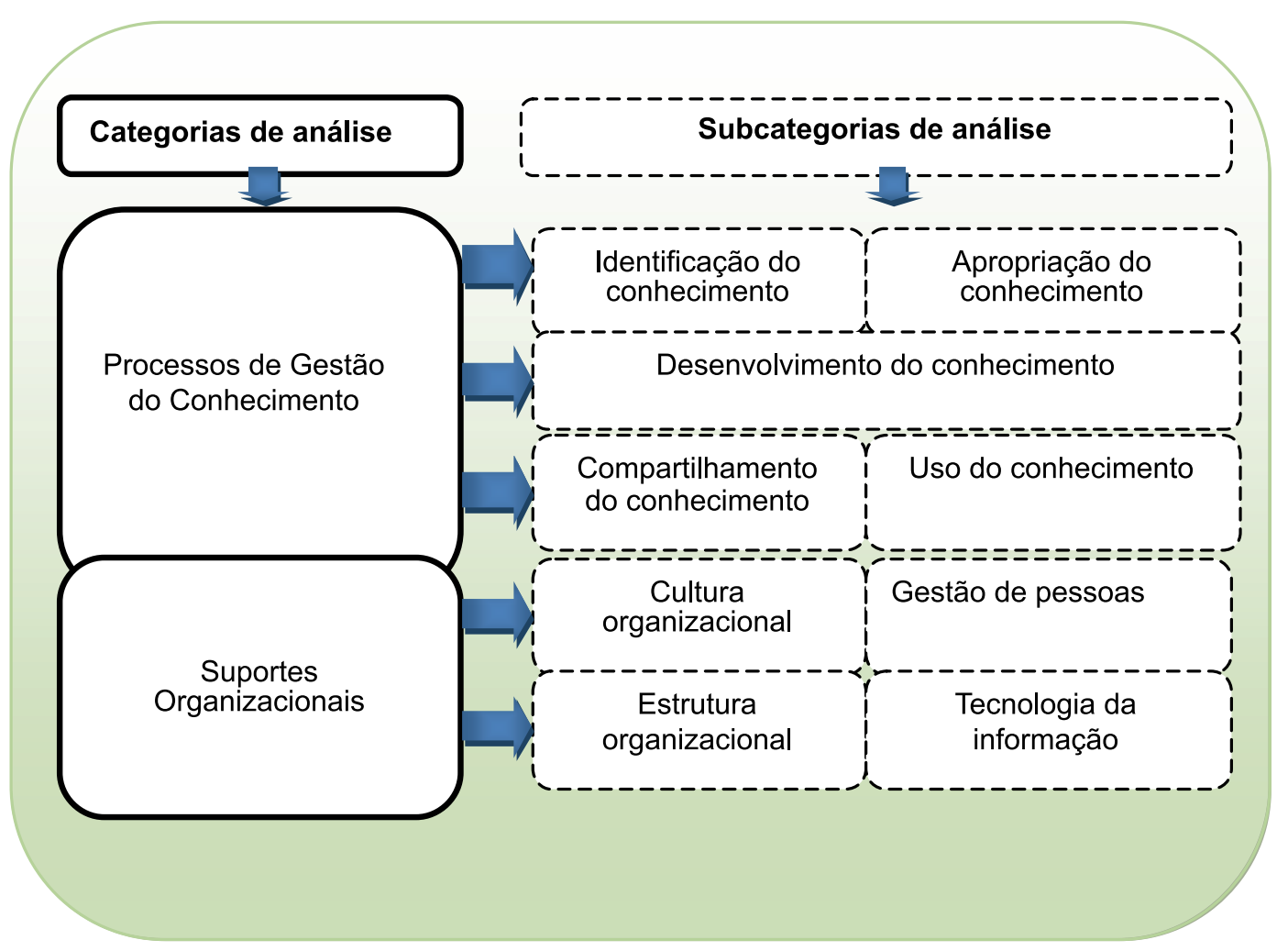

Figura 3 - Esquema categorial Fonte: Adaptado de Castro (2005).

Com base nessas categorias e subcategorias, a seguir apresentam-se a análise e a discussão dos resultados. Para preservar o anonimato dos participantes, os entrevistados foram identificados por: E1, E2, E3 e E4.

\section{ANÁLISE E DISCUSSÃO DOS RESULTADOS}

Conforme mencionado, os resultados apresentados nesta seção estão organizados em categorias e subcategorias.

\subsection{Processos de Gestão do Conhecimento}

A Identificação do Conhecimento possibilita a análise e descrição do ambiente de conhecimento da organização. Em relação à identificação das fontes de conhecimento em seus setores, o entrevistado 2 assim se manifestou: "eu acho que ali 
na Divisão de Aquisição as fontes são conhecidas pela experiência, já se tem essa noção de onde buscar a informação, mas não tem nenhum lugar escrito isso" (E2).

Da mesma forma, os demais entrevistados informaram que as fontes de conhecimento são identificadas informalmente em seus setores. Probst, Raub e Romhardt (2002, p. 62) afirmam que "tanto o conhecimento interno quanto externo, não é automaticamente visível, por isso as organizações devem criar transparência". Em outras palavras, os autores sugerem a criação de ferramentas como mapas de conhecimento, que são uma espécie de guia para identificar especialistas e pessoas com conhecimento em determinados assuntos dentro e fora da instituição. No caso desta unidade, constatou-se a ausência de mecanismos formais para identificar e tornar os conhecimentos visíveis a todos os colaboradores, o que dificulta a verificação das lacunas de conhecimento, tornando-se mais difícil identificar os conhecimentos que ainda faltam ou necessitam ser desenvolvidos.

Em relação à Aquisição do Conhecimento, observa-se a falta de programação ou estratégias para tal: “...não existem estratégias definidas” (E2); “...não se tem um cronograma, as capacitações [...] elas vêm da própria curiosidade, ou da vontade, ou do perfil de alguns membros da equipe [...]" (E4).

Portanto, evidencia-se que a Aquisição do Conhecimento acontece quando surge a demanda ou quando os servidores demonstram interesse. No entanto, a biblioteca além de provedora e organizadora de conhecimento, para servir a seus usuários, é também um órgão que necessita de conhecimento para realizar as suas tarefas e agregar valor aos serviços de uma instituição na sociedade do conhecimento (Bem, 2015).

Em relação ao Desenvolvimento do Conhecimento, Nonaka e Takeuchi (1997), afirmam que a criação do conhecimento organizacional "[...] é um processo em espiral, que começa no nível individual e vai subindo, ampliando comunidades de interação que cruzam fronteiras entre seções, departamentos, divisões e organizações". Nessa perspectiva, buscou-se investigar junto aos gestores a existência de alguma comunidade de prática na biblioteca. Os resultados apontaram que não existem grupos com essas características nessa unidade.

Outra forma de desenvolver o conhecimento, no âmbito das bibliotecas universitárias, é por meio da aproximação e da compreensão das necessidades informacionais dos usuários (Castro, 2005). Sobre esse aspecto, o entrevistado 1 relatou a seguinte situação:

Nós temos dois setores na biblioteca que fazem essa comunicação com o usuário, são esses dois setores que fazem essa leitura, ela não é padronizada, a leitura é trazida 
como uma demanda de uma nova necessidade e a gente vai fazendo as adaptações para o atendimento. Mas não é uma demanda que chega padronizada ou formalizada, que ficasse no histórico da administração da biblioteca, dizendo que mudanças estratégicas foram feitas pra atendimento de determinada demanda em determinado momento (E1).

Com base nesse depoimento, observou-se a necessidade de uma melhor estruturação dos canais de comunicação e aproximação com os usuários, a fim de que suas demandas sejam formalizadas e registradas, possibilitando, assim, que se estabeleçam estratégias e programações para que novos conhecimentos sejam desenvolvidos para atendê-las.

Sobre o Compartilhamento do Conhecimento, as informações obtidas juntos aos entrevistados indicam que os colaboradores costumam compartilhar seus conhecimentos e experiências, entretanto, mencionaram algumas barreiras. A existência de mais de um turno de trabalho foi apontada como uma barreira física, enquanto a resistência por parte de alguns servidores em compartilhar seus conhecimentos foi mencionada como uma barreira comportamental.

Em relação ao Uso do Conhecimento, Probst, Raub e Romhardt (2002) afirmam que não é suficiente que sejam executados com sucesso os processos de aquisição, desenvolvimento e compartilhamento dos conhecimentos, é necessário que ocorra a sua efetiva utilização para que se transformem em resultados concretos. Dessa forma, buscou-se identificar junto aos gestores a existência de mecanismos para facilitar a utilização do conhecimento.

Não existe, eu acho que não existe na nossa biblioteca como um todo [...] já participei de algumas reuniões de bibliotecários em 2017, já se discutia como que a gente poderia ter algum software, alguma coisa que ajudasse a registrar ata de reunião, ou a gente costuma fazer áudio de reuniões, onde ficam esses áudios? Não tem nenhum lugar na instituição onde possa armazenar (E2).

"Eu posso dizer que não, que não existe, atualmente não existe isso, o que existe são os drives, os e-mails" (E3).

"A gente usa atualmente o drive pessoal, salva no drive, só que aí não tem segurança nenhuma, se aquilo vai ser modificado, deletado, preservado" (E4).

Com base nesses depoimentos, observa-se que não existe uma base de conhecimento, pois cada setor tem seus próprios arquivos. Entretanto, ressalta-se 
que essa não é a forma mais adequada, sendo que o entrevistado 4 manifestou essa preocupação. Portanto, pode-se dizer que o sistema de armazenamento do conhecimento adotado pela biblioteca necessita de aprimoramento.

\subsection{Suportes Organizacionais}

Os Suportes Organizacionais representam a base sobre a qual os outros processos anteriormente mencionados possam apoiar-se. No modelo de Castro (2005), os Suportes Organizacionais compreendem a Cultura Organizacional, a Gestão de Pessoas, a Estrutura Organizacional e a Tecnologia da Informação.

A Cultura Organizacional pode ser compreendida como um conjunto de valores que determinados membros compartilham dentro de uma organização e que possibilita a essa se diferenciar das demais (Robbins, 2005). Acerca disso, dois gestores consideram que existe uma cultura favorável ao compartilhamento do conhecimento, conforme se observa em suas falas: "no meu setor sim, ali internamente nós trocamos muitas informações [...]" (E3).

Eu acredito que é uma equipe bastante entrosada, eu acho que tem pessoas ali com bastante experiência [...] que já viram muita coisa, não só no setor, mas na biblioteca como um todo, na universidade como um todo, e essa troca de ideia é constante lá dentro. (E2)

Em contraste a isso, o entrevistado 4 afirma que em seu setor existe certa resistência em compartilhar, mas, principalmente, em relação a aprender novos conhecimentos, conforme se observa na sua narrativa: “...tem realmente uma certa resistência, há uma certa acomodação, acho que isso é do ser humano [...], eu fiz aquilo com certa excelência e depois eu não quero me apropriar de outras" (E4).

Diante do exposto, os gestores poderão desenvolver estratégias que visem à conscientização dos colaboradores que atuam na biblioteca sobre a necessidade de contribuírem com a melhoria dos serviços, bem como de auxiliarem no crescimento e desenvolvimento do outro. Isso porque as mudanças culturais podem acontecer de duas formas: revolucionariamente, através da incorporação de esquemas interpretativos antagônicos aos anteriores, fazendo com que ocorra uma reestruturação completa do agir organizacional ou, gradualmente, por meio da incorporação de valores que complementam os já existentes, transformando-os (Richter, 2008). Para tal, uma política de Gestão de Pessoas é fundamental para dar suporte à cultura, à motivação e à troca de conhecimentos entre as pessoas.

Considerando que as pessoas são as verdadeiras criadoras do conhecimento e agentes de transformação, cabe à organização proporcionar as condi- 
ções ambientais que possibilitem o desenvolvimento de suas potencialidades e atividades inovadoras (Angeloni, 2008). Acerca de incentivos aos colaboradores para participarem de eventos ou cursos, o entrevistado 1 fez a seguinte afirmação: "toda manifestação de necessidade de uma capacitação, viagem pra algum evento, a direção recebe e encaminha essa solicitação [...] (E1).

No entanto, esse entrevistado referiu que existe um baixo interesse por parte dos servidores em participarem de cursos, conforme se observa na sua fala: "a PROGEP tem toda uma série de capacitações [...], ninguém manifestou alguma coisa que chegasse ao meu conhecimento para participar disso, com exceção de dois ou três servidores" (E1).

Sobre as principais perdas de conhecimento na biblioteca, os entrevistados apontaram as aposentadorias e as trocas de gestão. Ao verificar se existia algum plano ou método em discussão para evitar ou reduzir esse problema, constatouse que a biblioteca não dispõe de método formalizado, apenas algumas iniciativas isoladas, conforme relatou o entrevistado 1:

Tem o setor de processos [Divisão de Processos Técnicos], principalmente, que tem isso mais formalizado, porque eles têm essa necessidade e é um comprometimento da biblioteca como local estratégico de padronização técnica das bibliotecas [...], mas os outros setores têm movimentos incipientes [...] (E1).

Em relação à Estrutura Organizacional, Child (1977) defende que o desenho e redesenho desse suporte constitui uma das maiores prioridades da administração, pois sua função é auxiliar no alcance dos objetivos organizacionais. Desse modo, os gestores foram convidados a expor suas percepções sobre aspectos como: centralização/descentralização e comunicação organizacional.

Sobre esses aspectos, os gestores avaliaram da seguinte forma:

"É uma estrutura bastante centralizadora [...], sinto falta de uma comunicação lateral melhor também". (E2). "Na minha percepção, existem muitos assuntos que ainda são centralizados, centralizados principalmente na figura ou do diretor da biblioteca, ou na figura dos chefes das divisões" (E4).

O entrevistado 1 fez a seguinte observação: "a comunicação na biblioteca é falha, [...], identifiquei isso desde os primeiros momentos que vim trabalhar aqui, nos anos subsequentes, e agora, de alguma forma, também tenho repetido isso, noto em mim é um mea culpa [...]" (E1).

Com base no exposto, verifica-se que as decisões tendem a ser mais centralizadas e que a comunicação organizacional apresenta algumas falhas. Desse 
modo, ressalta-se que esses aspectos necessitam ser aprimorados, pois o trabaIho em equipe, a flexibilidade organizacional e a busca de novas formas organizacionais para se adaptar às demandas do ambiente, podem influenciar no processo de Gestão do Conhecimento (CASTRO, 2005).

No que se refere à Tecnologia da Informação (TI), suas ferramentas podem colaborar para melhorar o desempenho das tarefas e atividades rotineiras dentro das organizações, mas também podem ser utilizadas para apoiar a Gestão do Conhecimento, a exemplo dos mapas de conhecimento, de espaços colaborativos virtuais e de base de conhecimento. De acordo com Probst, Raub e Romhardt (2002), a base de conhecimento organizacional consiste em conhecimentos individuais e coletivos que a organização pode utilizar para realizar suas tarefas. Entretanto, identificou-se junto aos gestores a inexistência de mapa e de base de conhecimento, bem como a baixa utilização de espaços colaborativos virtuais.

Todavia, apesar da relevância das ferramentas tecnológicas, Davenport e Prusak (1998) alertam que mesmo que a organização disponha de $\mathrm{Tl}$, elas por si só serão inúteis se as informações armazenadas não forem compartilhadas ou utilizadas pelos colaboradores, ou seja, é necessário que haja uma cultura favorável.

\section{CONSIDERAÇÕES FINAIS}

Este estudo teve por objetivo compreender como ocorre a Gestão do Conhecimento em uma biblioteca universitária de uma Instituição Federal de Ensino Superior a partir de extratos do modelo de diagnóstico de Castro (2005). Em relação aos processos de Identificação, Aquisição, Desenvolvimento, Compartilhamento e Uso do Conhecimento, os quais representam os Processos de Gestão do Conhecimento descritos pela autora (2005), constatou-se que são realizados de forma não estruturada, o que dificulta o fluxo do conhecimento dentro da organização.

No que tange aos Suportes Organizacionais, os resultados indicam que existe uma cultura voltada ao Compartilhamento do Conhecimento, ainda que existam algumas barreiras físicas e comportamentais. Com relação à Gestão de Pessoas, constatou-se a necessidade de algumas medidas como o estabelecimento de uma política para estimular a apropriação e o desenvolvimento de novos conhecimentos, bem como a definição de métodos para minimizar as perdas de conhecimento em decorrência das aposentadorias e das trocas de gestão.

No que se refere à Estrutura Organizacional, constatou-se que o processo decisório tende a ser centralizado e que a comunicação organizacional apresenta algumas falhas, o que evidenciou a necessidade de aprimoramentos. Os 
resultados também demonstraram que as ferramentas de Tecnologia da Informação utilizadas não são suficientes para apoiar efetivamente os Processos de Gestão do Conhecimento, especialmente, em relação ao armazenamento dos conhecimentos.

Os resultados sugerem que a temática deve ser aprofundada no âmbito da biblioteca, pois se verificou que a Biblioteca Central da UFSM tem algumas potencialidades, mas também alguns desafios, tendo em vista que a Gestão do Conhecimento ocorre de forma não estruturada. Portanto, entende-se que o diagnóstico aqui realizado poderá contribuir para que as ações de melhoria que venham a ser implementadas possam ser direcionadas aos aspectos humanos, estruturais e tecnológicos, visto que ficou evidenciado que tais aspectos, em conjunto, possibilitam a efetividade da Gestão do Conhecimento.

\section{REFERÊNCIAS}

Angeloni, M. T. (Org.). (2008). Organizações do conhecimento: infra-estrutura, pessoas e tecnologias. (2. ed). São Paulo: Saraiva.

Batista. F. F. (2012). Modelo de gestão do conhecimento para a administração pública brasileira: como implementar a gestão do conhecimento para produzir resultados em benefício do cidadão. Brasília: Ipea.

Bem, R. M. de. (2015). Framework de gestão do conhecimento para bibliotecas universitárias. 344 p. (Tese de Doutorado, Universidade Federal de Santa Catarina, Florianópolis).

Castro, G. de. (2005). Gestão do conhecimento em biblioteca universitária: um instrumento de diagnóstico. 160p. (Dissertação de Mestrado, Universidade Federal de Santa Catarina, Florianópolis).

Child, J. (1972). Organizational structure, environment and performance: the role of strategic choice. Sociology, 6, 1-22.

Davenport, T. H., \& Prusak, L. (1998). Conhecimento empresarial: como as organizações gerenciam o seu capital intelectual. (6. ed). Rio de Janeiro: Campus.

Gil, A. C. (2002). Como elaborar projetos de pesquisa. (4. ed). São Paulo: Atlas.

Islam, M. A., Agarwal, N. K., \& Ikeda, M. (2017). Effect of knowledge management on service innovation in academic libraries. IFLA Journal, 43(3), 266-281.

Jorge, C. F. B, \& Sutton, M. J. D. (2016). Games como estratégias na construção e gestão do conhecimento no contexto da Inteligência Organizacional [Número especial]. Perspectivas em Gestão \& Conhecimento, 6, 103-118.

Lacombe, F. J. M., \& Heilborn, G. L. J. (2008). Administração: princípios e tendên- 
cias. (2. ed). São Paulo: Saraiva.

Maciel, A. C., \& Mendonça, M. A. R. (2006). Bibliotecas como organizações. Rio de Janeiro: Interciência; Niterói: Intertexto.

Marouf, L. (2017). Are academic libraries ready for knowledge management? The Electronic Library, 35(1), 137-151.

Moraes, R. (2003). Uma tempestade de luz: a compreensão possibilitada pela análise textual discursiva. Revista Ciência e Educação, 9(2), 191-211.

Nonaka, I, \& Takeuchi, H. (1997). Criação de conhecimento na empresa: como as empresas japonesas geram a dinâmica da inovação. (13. ed). Rio de Janeiro: Elsevier. . (2008). Gestão do Conhecimento. Porto Alegre: Bookman.

Probst, G., Raub, S., \& Romhardt, K. (2002). Gestão do conhecimento: os elementos construtivos do sucesso. Porto Alegre: Bookman.

Richter, F. A. (2008). A cultura organizacional e seus fundamentos frente à gestão do conhecimento. In: ANGELONI, M. T. (Org). Organizações do conhecimento: infraestrutura, pessoas e tecnologias. (2. ed). São Paulo: Saraiva.

Robbins, S. P. (2005). Comportamento organizacional. São Paulo: Pearson Prentice Hall.

Rossi, T. et al. (2017, Setembro/Dezembro). A gestão do conhecimento sob o ponto de vista de sua coordenação: estratégia, treinamento e planejamento. Informação \& Informação, Londrina, 22(3), 535-555.

Santos, R. R. (2015). Gestão dos dispositivos de comunicação da web social: potencializando as atividades de mediação da informação e do conhecimento em bibliotecas universitárias brasileiras. 305 p. (Tese de Doutorado, Universidade Federal da Paraíba, João Pessoa)

Silva, A. N. da. (2013). Proposta de um instrumento para diagnóstico da gestão da informação e do conhecimento (GIC) de forma integrada para bibliotecas universitárias. 142 p. (Dissertação de Mestrado, Universidade Federal da Paraíba, João Pessoa)

Sveiby, K. E. (1998). A nova riqueza das organizações. Rio de Janeiro: Campus.

Yin, R. K. (2015). Estudo de Casos: planejamento e métodos. (5. ed). Porto Alegre: Bookman. 